\title{
Changes in plasma and urinary nitrite after birth in premature infants at risk for necrotizing enterocolitis
}

\author{
Priti Pun', Jesica Jones ${ }^{1}$, Craig Wolfe', Douglas D. Deming ${ }^{1}$, Gordon G. Power ${ }^{2}$ and Arlin B. Blood ${ }^{1,2}$
}

BACKGROUND: Plasma nitrite serves as a reservoir of nitric oxide (NO) bioactivity. Because nitrite ingestion is markedly lower in newborns than adults, we hypothesized plasma nitrite levels would be lower in newborns than in adults, and that infants diagnosed with necrotizing enterocolitis (NEC), a disease characterized by ischemia and bacterial invasion of intestinal walls, would have lower levels of circulating nitrite in the days prior to diagnosis.

METHODS: Single blood and urine samples were collected from 9 term infants and 12 adults, 72 preterm infants every $5 \mathrm{~d}$ for 3 wk, and from 13 lambs before and after cord occlusion.

RESULTS: Nitrite fell $50 \%$ relative to cord levels in the first day after birth; and within $15 \mathrm{~min}$ after cord occlusion in lambs. Urinary nitrite was higher in infants than adults. Plasma and urinary nitrite levels in infants who developed NEC were similar to those of preterm control infants on days 1 and 5 , but significantly elevated at 15 and $20 \mathrm{~d}$ after birth.

CONCLUSION: Plasma nitrite falls dramatically at birth while newborn urinary nitrite levels are significantly greater than adults. Acute NEC is associated with elevated plasma and urinary nitrite levels.

T he free radical molecule nitric oxide (NO) plays a key signaling role in a number of physiological processes. NO is produced from L-arginine by the action of NO synthase enzymes found throughout the body. NO can diffuse readily through tissues to distances several cells away from its site of production. However, its half-life in whole blood is $<10 \mathrm{~ms}$ and thus the range of free NO itself is paracrine in nature (1). As a free radical, NO can be metabolized by a number of different biochemical pathways. Many of these pathways result in nitrogen oxide species (NOx) that are stable enough to circulate systemically yet retain the bioactivity of $\mathrm{NO}$, such as nitrite and nitrosothiols. Other pathways oxidize free NO to nitrate. While nitrate is inert in mammalian cells, it can be secreted in saliva and converted to nitrite by oral bacteria (2), although this pathway is markedly diminished in the newborn compared to the adult (3). These products of NO metabolism make up a humoral source of NO bioactivity (see review by Lundberg and Weitzberg (4)). Thus, it is now recognized that the overall level of NO bioactivity in tissues is a result of not only local NO synthase activity, but also the concentration of NOx, which may be delivered from other organs via the blood.

There is accumulating evidence that nitrite plays a role in the regulation of cardiovascular homeostasis and responses to hypoxic/ischemic stress. Numerous studies have demonstrated the positive effects of increasing dietary nitrate intake and subsequent elevation in plasma nitrite concentrations on exercise performance and lowering blood pressure (5). Modest increases in blood nitrite levels also confer protection in animal models of ischemia/reperfusion injury in the brain, heart, liver, kidney, and lung (6). The bioactivity of nitrite results from its conversion to NO by reaction with a number of metalcontaining proteins with nitrite reductase activity (7), a reaction that is favored in hypoxic/ischemic tissues.

Infants born prematurely are at increased risk of systemic hypoxia and compromised cardiovascular homeostasis during the first few days of life. This dysregulation of tissue oxygen delivery is proposed to contribute to necrotizing enterocolitis (NEC), a gastrointestinal disease that affects $5-14 \%$ of infants born weighing less than $1,500 \mathrm{~g}$ (8). While premature birth is a prominent risk factor, the underlying cause of NEC remains unknown. Although there is little evidence to support the idea that NEC is caused by a single acute perinatal ischemic event (9), poor splanchnic oxygenation and reduced blood flow are associated with increased incidence of NEC (10), and histological evidence of (11). In the adult rodent gastrointestinal tract, swallowed salivary nitrite, derived from the reduction of salivary nitrate by oral bacteria, confers protection by increasing mucus production, improving local blood flow, killing bacterial pathogens, decreasing inflammation, and improving epithelial injury (5). The role that nitrate and nitrite play in regulating gastrointestinal blood flow in the newborn has not been studied.

We have previously demonstrated that newborn infants have lower blood nitrite concentrations than adults, possibly due to markedly lower levels of nitrate and nitrite ingestion (12). Preterm infants in particular ingest 50\% less nitrite than term infants (12), leading us to hypothesize that nitrate and nitrite levels would be decreased in preterm compared to term infants. Furthermore, given animal evidence for the protective effects of nitrite in the gastrointestinal tract, we hypothesized 
infants diagnosed with NEC would have lower levels of circulating nitrite in the days prior to diagnosis. We tested this hypothesis by measuring plasma nitrate and nitrite and urine nitrite concentrations in preterm infants over the first $3 \mathrm{wk}$ of life and making comparisons between infants who developed NEC and those who did not.

\section{RESULTS}

Nitrite concentrations were measured in blood and urine collected from 79 preterm infants, 9 healthy term infants, 12 adults, and 12 cord blood samples. Of the 79 preterm infants, 6 infants developed Bell's stage 2A NEC. The time of NEC diagnosis ranged from 9 to $29 \mathrm{~d}$ after birth (mean $17 \mathrm{~d}$ ). Six preterm infants without NEC developed sepsis and were excluded from analysis because plasma nitrite and nitrate levels have been shown to be elevated in pediatric and neonatal patients with sepsis $(13,14)$. One preterm infant died on the 18 th day of life with an isolated ileal perforation and was excluded from the analyses. Thus, 66 preterm infants without NEC were analyzed. The demographics of the patients are provided in Table 1.

\section{Nitrite and Nitrate Concentrations in Infant Plasma}

Twelve to $24 \mathrm{~h}$ after birth, nitrite concentrations of preterm infants $(0.03 \pm 0.01 \mu \mathrm{mol} / \mathrm{l})$ were lower than term infants

Table 1. Preterm patient demographics

\begin{tabular}{|c|c|c|c|}
\hline & Preterm & $\begin{array}{c}\text { Preterm with } \\
\text { necrotizing enterocolitis }\end{array}$ & Term \\
\hline Participants ( $n$ ) & 66 & 6 & 9 \\
\hline Gestational age (weeks) & $29.6 \pm 0.2$ & $28.1 \pm 0.9$ & $38.4 \pm 0.3$ \\
\hline Birth weight (grams) & $1,349 \pm 41$ & $1,224 \pm 128$ & $2,791 \pm 282$ \\
\hline Male $(n)$ & 26 & 5 & 4 \\
\hline Female $(n)$ & 31 & 1 & 5 \\
\hline Mean day of diagnosis & - & 17 & - \\
\hline
\end{tabular}

$(0.08 \pm 0.01 \mu \mathrm{mol} / \mathrm{l} ; P<0.05)$, cord blood samples $(0.18 \pm 0.01$ $\mu \mathrm{mol} / \mathrm{l}, P<0.001)$, and adults $(0.16 \pm 0.01 \mu \mathrm{mol} / \mathrm{l}, P<0.001)$. Plasma nitrite levels in term infants tended to be lower than cord blood and adult levels, but post hoc analysis did not indicate statistical significance. Plasma nitrite concentrations of preterm infants increased significantly during the $20 \mathrm{~d}$ after birth $(P<0.001$, Figure 1$)$.

Plasma nitrate concentrations of term infants $(16.4 \pm 1.5 \mu \mathrm{mol} / \mathrm{l}) \quad 12-24 \mathrm{~h}$ after birth were lower than those of preterm infants $(25.3 \pm 1.7 \mu \mathrm{mol} / \mathrm{l}, P<0.05)$, cord blood samples $(33.1 \pm 3.5 \mu \mathrm{mol} / \mathrm{l}, P<0.01)$, and adults $(33.4 \pm 3.1 \mu \mathrm{mol} / \mathrm{l}, P<0.01)$ (Figure $1 \mathrm{~b})$. One-way ANOVA indicated that there was significant variation in plasma nitrate concentrations of preterm infants over the first $20 \mathrm{~d}$ after birth $(P=0.014)$.

\section{Nitrite Concentrations in Newborn Lambs}

The markedly lower nitrite concentrations on the first day after birth led us to examine the time course of changes in plasma nitrite concentrations in more detail in 13 newborn lambs. Prior to ligation of the cord, plasma nitrite concentration in umbilical arterial blood was $0.16 \pm 0.01 \mu \mathrm{mol} / \mathrm{l}$. Fifteen minutes after birth, nitrite concentrations had fallen to $0.06 \pm 0.01$ $\mu \mathrm{mol} / \mathrm{l}(P<0.001)$, and remained low for at least $180 \mathrm{~min}$ (Figure 2).

\section{Nitrite Concentrations in Urine}

On the first day after birth, urinary nitrite concentrations averaged $0.49 \pm 0.05 \mu \mathrm{mol} / \mathrm{l}$ in preterm infants and $0.50 \pm 0.05$ $\mu \mathrm{mol} / \mathrm{l}$ in term infants, values not significantly different from one another (Figure 1c). The levels in both preterm and term infants on day 1 were significantly higher than the levels measured in urine collected from adults $(0.07 \pm 0.01 \mu \mathrm{mo} / \mathrm{l}$, $P<0.001)$. In preterm infants, the urine nitrite concentrations increased significantly over the first $20 \mathrm{~d}$ after birth $(P<0.01$, Figure 1c). a

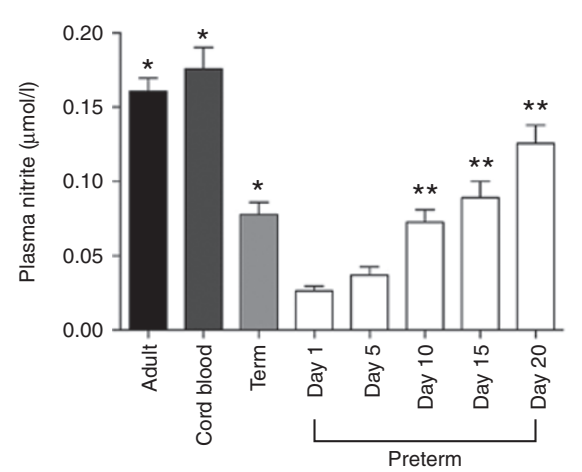

b

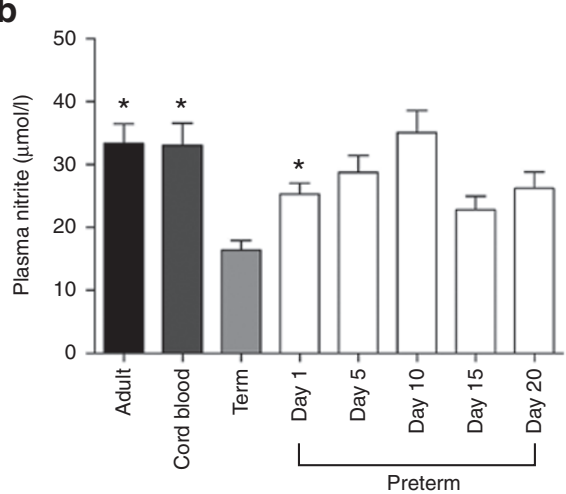

C

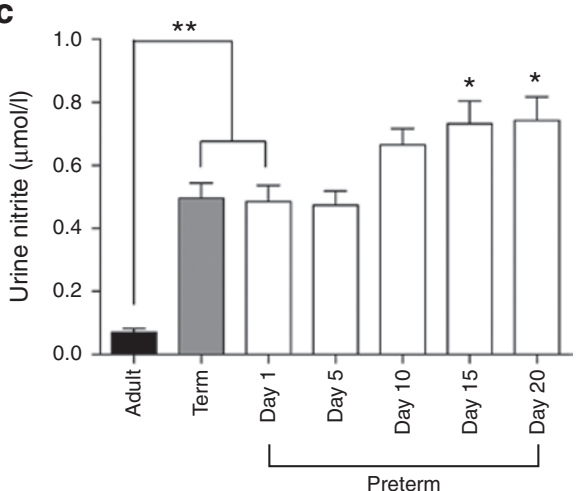

Figure 1. Plasma nitrite and nitrate and urine nitrite concentrations. (a) Plasma nitrite concentrations were significantly higher in adults, cord blood, and term infants than in preterm infants on the first day after birth $\left(^{*}=\right.$ difference from preterm infants on day $\left.1, P<0.05\right)$. Nitrite concentrations increased over the first $20 \mathrm{~d}$ after birth, with days 10,15 , and 20 greater than day $1(* * P<0.01)$. (b) On day 1 , plasma nitrate concentrations in term infants were significantly lower than those of adults, cord blood, and preterm infants $\left({ }^{*}=\right.$ difference from term infants, $\left.P<0.05\right)$. The variation in preterm nitrate levels over the first $20 \mathrm{~d}$ after birth was also significant $(P<0.01)$, although post-hoc analysis did not detect a significant difference between day 1 and any subsequent time point. (c) Urine nitrite concentrations in preterm and term infants on day 1 were significantly higher than those of adults $\left({ }^{* *} P<0.001\right)$. Urinary nitrite concentrations of preterm infants increased over the first $20 \mathrm{~d}$ of life, with concentrations on days 15 and 20 being significantly greater than days 1 and $5\left({ }^{*} P<0.05\right)$. 


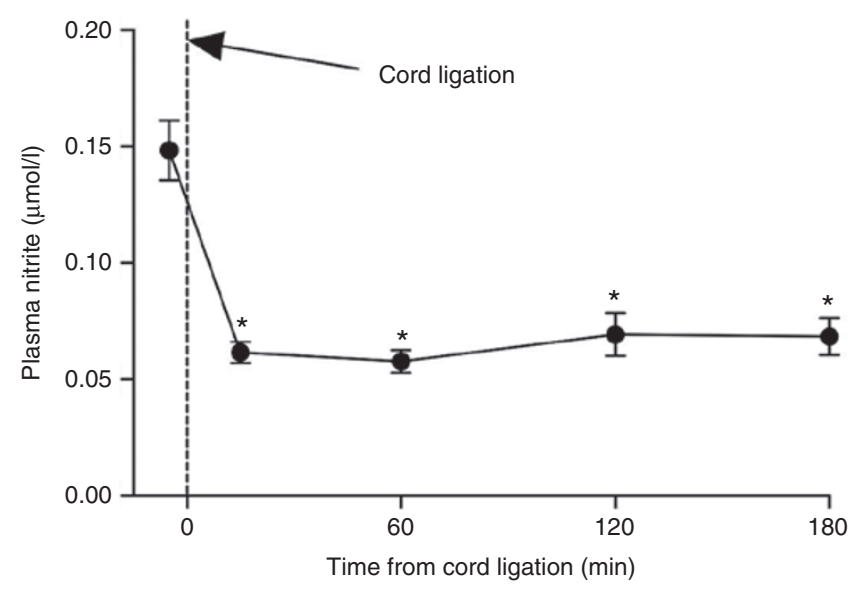

Figure 2. Plasma nitrite concentrations in fetal sheep before and after ligation of the umbilical cord and initiation of ventilation. Within $15 \mathrm{~min}$ following birth, nitrite concentrations had fallen by $>60 \%\left({ }^{*} P<0.001\right.$ compared to baseline) and remained lower than baseline 60,120 , and 180 min after birth.

\section{Plasma Nitrite and Nitrate Concentrations in Preterm Infants With and Without NEC}

Plasma nitrite and nitrate concentrations in those preterm infants who developed NEC were not significantly different than those of control preterm infants on days 1 and 5 . On days 10, 15, and 20, plasma nitrite concentrations were higher in preterm infants who developed NEC than in control preterm infants, with post-hoc analysis indicating significance between the two groups on days 15 and $20(P<0.05$, Figure 3a,b). Plasma nitrite concentrations of preterm infants with NEC increased over the first $20 \mathrm{~d}$ after birth $(P<0.01)$. Although plasma nitrate concentrations tended to increase in infants with NEC, this change did not meet the criteria for significance $(P=0.09)$. Individual and mean plasma nitrite and nitrate concentrations on days relative to diagnosis with NEC are included in Supplementary Figure S1 online.

\section{Urine Nitrite Concentrations in Preterm Infants With and Without NEC}

On days 10, 15, and 20, plasma nitrite concentrations were higher in the preterm infants who developed NEC than in control preterm infants, with post-hoc analysis indicating significance on days 15 and $20(P<0.01)$. Urine nitrite concentrations of preterm infants with NEC increased over the first $20 \mathrm{~d}$ after birth $(P<0.001)$. Individual and mean urine nitrite concentrations on days relative to diagnosis with NEC are included in Supplementary Figure S1 online.

\section{DISCUSSION}

The current study tested the hypotheses that plasma nitrite levels fall significantly at birth, that levels in preterm infants fall below those of term infants, and that infants diagnosed with NEC would have lower levels of circulating nitrite in the days prior to diagnosis. We found that the plasma nitrite concentrations of preterm infants on the first day of life were lower than those of term infants, adults and placental cord blood, a difference also observed to appear in newborn lambs within 15 min after birth. Contrary to our hypothesis, plasma and urine nitrite levels of preterm infants who developed NEC were similar to those of their non-NEC counterparts on days 1 and 5 after birth. Once NEC became apparent, plasma and urine nitrite concentrations were measurably higher than those of non-NEC counterparts 15 and $20 \mathrm{~d}$ after birth.

\section{Decrease in Plasma Nitrite and Nitrate Concentrations at Birth}

Several reasons might account for the marked decrease in plasma nitrite in the minutes and hours after birth. Previous studies have shown that up to $70 \%$ of plasma nitrite is derived from NO produced by eNOS (15). Several studies have assessed the effects of development on organ-specific eNOS levels $(16,17)$, but, to our knowledge, none have measured whole body eNOS activity in newborns. Preterm infants are deficient in arginine which could lead to decreased NO synthesis from eNOS (18). Neonates also have two- to threefold higher concentrations of asymmetric dimethylarginine (ADMA), an endogenous inhibitor of NOS, compared to adults (19). Thus, low L-arginine and increased ADMA concentrations may lead to low eNOS activity in newborns, contributing to the fall in plasma nitrite levels after birth.

It is also possible that the mother and placental tissue constitute a significant source of fetal nitrite that is lost at birth. We have previously reported that nitrite concentrations of chronically instrumented fetal sheep are the same as those of the mother under normoxic conditions, but become twofold higher than the ewe following long-term exposure to moderate hypoxia (20). This finding suggests transport of nitrite from the ewe into the fetus, production of nitrite by placental tissue, or an accelerated rate of nitrite production in the fetus in response to hypoxia. These possibilities have not been evaluated experimentally but could influence the changes that occur soon after birth.

Although most plasma nitrite is derived from NO oxidation, this reaction is only one of a number of competing reactions by which NO is consumed. One of the fastest of these competing pathways is the reaction of NO with superoxide to form peroxynitrite. This reaction proceeds at a nearly diffusionlimited rate $\left(k=4.3\right.$ to $\left.20 \times 10^{9} \mathrm{M}^{-1} \cdot \mathrm{s}^{-1}\right)(21)$ and can become a significant scavenger of $\mathrm{NO}$ if superoxide concentrations are increased (22). While we are not aware of reported changes in whole body superoxide levels at birth, it is reasonable to hypothesize that the increases in arterial and tissue oxygen tensions that occur in the transition from fetus to newborn increase superoxide production that, in turn, scavenges NO away from nitrite production.

Regardless of the mechanism, the fall in nitrite levels at birth appears to be consistent with other cardiovascular homeostatic events that facilitate the vascular transition from a fetal state characterized by low pressures and high flows to a newborn state with higher overall resistance to blood flow. Factors that contribute to the increased vascular tone of the newborn include decreases in circulating vasodilators such as prostaglandin E2 (23) and adenosine (24), and increases 
in vasoconstricting catecholamines (25). Given the vasodilatory and NO-like bioactivity ascribed to nitrite (see review by Lundberg and Weitzberg (26)), the fall in concentrations within minutes of birth raises the possibility that nitrite may also play a role in the transition.

While circulating nitrate concentrations are of cardiovascular relevance to the adult due to its conversion to nitrite (26), the same may not be true for newborns as the activity of oral nitrate-reducing bacteria is markedly reduced (3). Plasma nitrate concentrations tended to decrease at birth, in parallel with nitrite concentrations, although the changes were less pronounced in the preterm infants. This may reflect the contribution of non-NO-related influences, such as denitrifying enzymes in the liver (27) or decreased renal excretion.

\section{Nitrite Concentration in Urine}

Although there are numerous reports of combined nitrite/ nitrate concentrations in newborn urine (see Honold et al. (28) for comprehensive measurements), we are unaware of previous reports of urine nitrite levels in healthy infants. Urinary nitrite concentrations are typically less than $5 \%$ of the total nitrite/ nitrate signal, thus the combined nitrite and nitrate level is not a useful indication of nitrite excretion. In fact, in contrast to our finding of higher urinary nitrite levels in infants compared to adults, Honold et al. (28) reported higher urinary nitrite/ nitrate concentrations in adults compared to preterm and term infants. Using the body weights of our infants and estimates of normal urinary output $\left(48 \mathrm{ml} \cdot \mathrm{kg}^{-1} \cdot \mathrm{day}^{-1}\right)$, one may calculate a urinary nitrite output for preterm infants of $3.6 \mu \mathrm{g} \cdot \mathrm{kg}^{-1} \cdot \mathrm{day}^{-1}$ and for term infants of $5.3 \mu \mathrm{g} \cdot \mathrm{kg}^{-1} \cdot \mathrm{day}^{-1}$. A similar calculation for a typical $70 \mathrm{~kg}$ adult with a urine output of $12 \mathrm{ml} \cdot \mathrm{kg}^{-1} \cdot \mathrm{day}^{-1}$ indicates a urinary nitrite output of only $0.24 \mu \mathrm{g} \cdot \mathrm{kg}^{-1} \cdot \mathrm{day}^{-1}$, about $5-10 \%$ of newborn output. This marked difference between newborns and adults cannot be explained by dietary intake, since newborns ingest less than $1 \%$ as much nitrite as adults when normalized to body weight (29). Interestingly, for newborns the urinary excretion of nitrite is significantly higher than their estimated dietary intake $\left(\sim 0.7 \mu \mathrm{g} \cdot \mathrm{kg}^{-1} \cdot \mathrm{day}^{-1}\right)$ (29), whereas excretion by adults is less than intake (109 $\left.\mu \mathrm{g} \cdot \mathrm{kg}^{-1} \cdot \mathrm{day}^{-1}\right)(30)$. This result suggests net endogenous production of nitrite by newborns and consumption by adults. Nitrite is actively reabsorbed in the kidney of adults via a pathway dependent upon carbonic anhydrase activity (31), and a deficiency in this pathway in newborns would also contribute to higher urinary nitrite levels, although this possibility remains to be studied.

\section{Possible Role for Nitrite in NEC}

Various lines of evidence suggest NO and nitrite potentially plays a protective role against NEC. L-arginine supplementation to promote eNOS activity has been shown to reduce the severity and risk of NEC $(32,33)$. Nitrite, serving as a source of $\mathrm{NO}$, protects against ischemia/reperfusion injury in a number of organs and animal models (6). In the gastrointestinal tract, NO derived from nitrite also protects against bacterial pathogens and supports thickening of the protective mucosal layer, and thus may support the barrier function of the gastrointestinal lining (5). Supplemental dietary nitrite is also protective in a mouse model of NEC (34). Thus, our hypothesis was that preterm infants with lower plasma nitrite levels during the first few days of life would be more likely to develop NEC. However, plasma nitrite levels of preterm infants destined to develop NEC were similar to healthy preterm controls, indicating that NEC is not caused by plasma nitrite levels that are lower than normal for a preterm infant. Notably, plasma nitrite levels were already markedly lower in preterm infants than in term infants and adults, and whether supplementation of nitrite would be protective requires further study.

In contrast to the proposed beneficial effects of nitrite and NO under physiological conditions, it appears that once NEC has reached an acute inflammatory stage, it has been postulated that excessive NO production from inducible NOS (iNOS) contributes to the disease progression (35). Resected sections of intestine from infants with acute NEC have increased levels of iNOS and iNOS knockout mice appear to be protected against LPS-induced bacterial translocation (36). Overproduction of NO by enhanced iNOS activity leads to toxic levels of reactive nitrogen oxide derivatives, like peroxynitrite, that are thought to contribute to the epithelial injury and disruption of repair mechanisms that lead to intestinal barrier failure characteristic of NEC (37). Consistent with overproduction of NO by iNOS, plasma nitrite and nitrate and urinary nitrite levels in infants developing NEC became significantly elevated 15 and $20 \mathrm{~d}$ after birth (Figure 3), suggesting that urinary nitrite levels could be a useful noninvasive biomarker of NEC. However, more rigorous studies need to be done to validate nitrite as a reliable marker for NEC. While the cause of this increase cannot be determined from the present study, it is worth noting that similar increases in urinary nitrite and/or nitrate are found in infants with systemic inflammatory responses (38), consistent with markedly increased iNOS activity.

\section{Clinical Perspective}

The current study finds that a marked fall in circulating nitrite concentrations occurs at birth. Given increasing evidence that nitrite plays a key role as a circulating source of NO, future studies are needed to establish the extent to which changes in nitrite concentrations contribute to the cardiovascular transition at birth, and whether manipulation of these concentrations might improve outcomes in infants exposed to hypoxic/ ischemic stress.

\section{METHODS}

Human protocols were preapproved by the Loma Linda University Institutional Review Board and written informed consent was obtained from a parent or legal guardian, or from the study subject (adult group). The animal protocol was preapproved by the Loma Linda University Institutional Animal Care and Use Committee.

\section{Human Protocol}

The infants studied in this investigation were patients in the neonatal intensive care unit or well baby nursery of Loma Linda University Children's Hospital (Loma Linda, CA). They fell into two groups: term infants born after $37 \mathrm{wk}$ and with a birth weight more than 2,500 g, and preterm infants born at a gestational age less than $32 \mathrm{wk}$. Preterm 


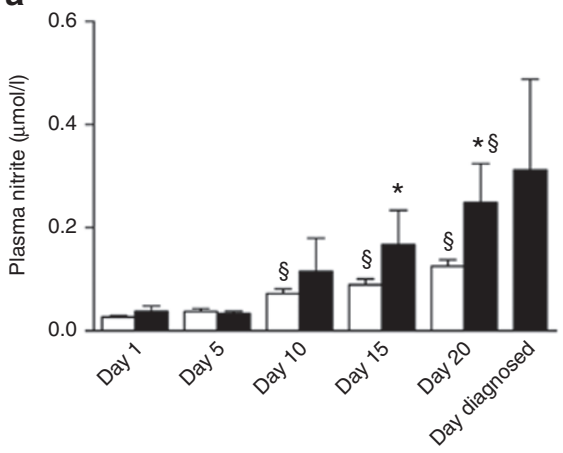

Time from birth b

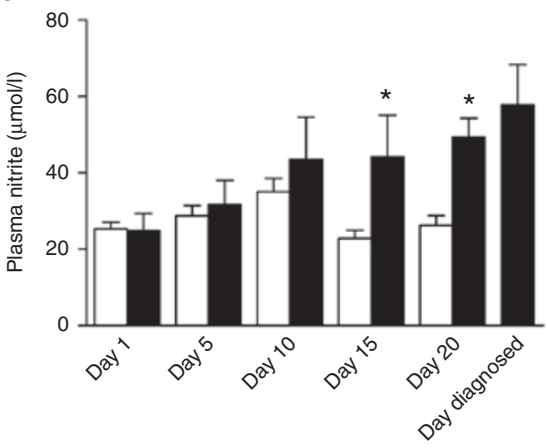

Time from birth

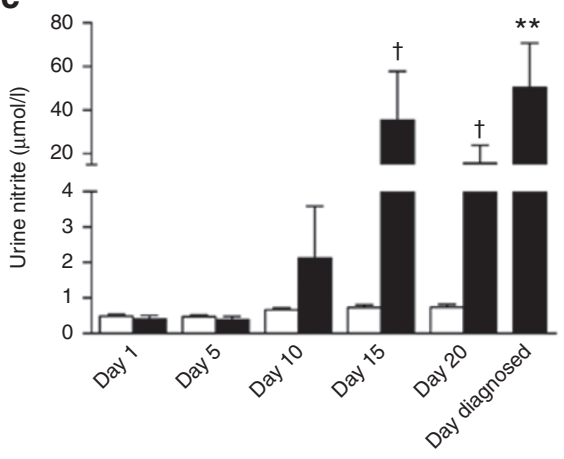

Time from birth

Figure 3. Plasma and urine nitrite concentrations in preterm infants with or without diagnosis of necrotizing enterocolitis (NEC). There were no significant differences between preterm infants with NEC (black bars) or without NEC (white bars) with respect to plasma nitrite (a) or nitrate (b) concentrations on days 1,5 , and 10 . In contrast, on days 15 and 20, plasma nitrite and nitrate levels were higher in preterm infants diagnosed with NEC compared to those without NEC $(* P<0.05)$. Nitrite concentrations increased over the first $20 \mathrm{~d}$ after birth for preterm infants with and without NEC ( $\S=$ difference from day 1 , $P<0.05)$. (c) Fifteen and $20 \mathrm{~d}$ after birth, urine nitrite concentrations in preterm infants who developed NEC were significantly higher than those of control preterm infants $\left({ }^{+} P<0.001\right)$. Nitrite concentrations in urine from the preterm infants with NEC increased over the first $20 \mathrm{~d}$ after birth, with levels on the day they were diagnosed with NEC (mean $=$ day 17 ) being significantly higher than the levels measured in these infants on days 1 and $5(* * P<0.05)$.

infants weighing less than $800 \mathrm{~g}$ were excluded from the study due to limitations in the amount of blood that could be collected. Also excluded were infants with congenital malformations or chromosomal abnormalities, those small for gestational age, intrauterine growth restricted, anemic $(\mathrm{Hgb}<11 \mathrm{~g} / \mathrm{dl})$ or septic (positive blood, urine, CSF cultures). The infants' gestational age, birth weight, gender, type of feeding (breast milk or formula), antibiotic therapy, whether a PDA ligation had been performed, and whether indomethacin or a blood transfusion had been given were noted.

Blood and urine samples were obtained from the preterm infants between 12 to $24 \mathrm{~h}$, and $5,10,15$, and $20 \mathrm{~d}$ of extrauterine life. Within this 20 - $d$ period, if an infant developed signs and symptoms of NEC (defined as Bell's stage 2A) an additional sample of blood and urine was collected within $24 \mathrm{~h}$ of diagnosis. Samples of placental cord blood were collected from term infants following uncomplicated cesarean section. Blood $(1 \mathrm{ml})$ and urine $(1-3 \mathrm{ml})$ samples were also collected from these term infants in conjunction with standard newborn screening tests at approximately $24 \mathrm{~h}$ of life. Single blood and urine samples were also collected from healthy adults (24-72 y of age).

\section{Fetal Sheep Protocol}

Fetal sheep were delivered via C-section at $124-126 \mathrm{~d}$ of gestation (term $=145)$ as part of another study protocol (39). Venous blood samples were collected for plasma nitrite measurement before birth and at 15,60,120, and $180 \mathrm{~min}$ after ligation of the umbilical cord. Samples were immediately centrifuged for $60 \mathrm{~s}$ at $10,000 \mathrm{rpm}$ and the plasma was decanted, frozen in liquid nitrogen, and stored at $-80^{\circ} \mathrm{C}$ for subsequent measurement of nitrite concentrations.

\section{Sample Collection and Handling}

Blood samples ( $1 \mathrm{ml}$ each) from newborn infants were collected from an indwelling catheter whenever possible; otherwise by heel stick timed so as to coincide with routine clinical care (blood glucose measurements, blood gas measurements, weekly nutrition labs, newborn screen). Blood was collected from adults by venipuncture of the antecubital vein. The blood was immediately centrifuged for $1 \mathrm{~min}$ at $10,000 \mathrm{~g}$. The plasma was stored at $-80^{\circ} \mathrm{C}$ until assay.

Urine samples (1-3 $\mathrm{ml}$ each) were collected by placing a cotton ball into the infant's diaper before urination. Sodium hydroxide $(0.1 \mathrm{M})$ was added to the urine sample in a $1: 1 \mathrm{ratio} \mathrm{v} / \mathrm{v}$ to stabilize nitrite, and the sample was then stored at $-80^{\circ} \mathrm{C}$ for subsequent nitrite analysis.

\section{Nitrite and Nitrate Assay}

Urine and plasma nitrite concentrations were measured by triiodide chemiluminescence (20), enabling quantification above 10 $\mathrm{nmol} / \mathrm{l}$ with a precision of $\pm 5 \mathrm{nmol} / \mathrm{l}$. Nitrate concentrations were measured by enzymatic reduction of nitrate to nitrite as previously described (3).

\section{Statistical Analysis}

An a priori power analysis was performed using $\mathrm{G}^{\star}$ Power (Heinrich Heine University, Dusseldorf, Germany), and indicated that with an effect size of $50 \%, P<0.05$, and $80 \%$ power, a total of six patients with NEC would be needed to detect a change in plasma and urine nitrite levels over time and compared to preterm controls. Data are presented as mean \pm SEM. Differences between study groups were detected using one-way ANOVA. A two-way ANOVA was used to compare samples from preterm infants with or without NEC. When ANOVA indicated significance, Bonferroni's post hoc analysis was applied to detect differences between sample pairs. A Kruskal-Wallis test was used to compare term, preterm, and adult plasma nitrite and nitrate levels due to a large variation in the small number of samples in the term and adult groups. Outlying values, likely due to nitrite or nitrate contamination occurring during sample collection, were identified and removed using the ROUT method (40) with a $Q$ value of $0.1 \%(0.1 \%$ chance of excluding a valid value). For comparisons between preterm infants with or without NEC, two-way ANOVA was applied to the day 1 and 5 data to test whether nitrite levels were lower in infants who would go on to develop NEC, and to days 10,15, and 20 to test whether nitrite levels were different in infants with developing or acute NEC. All statistical analyses were performed using Prism 6 for Mac OSX (Graphpad Software, La Jolla, CA), except for two-way ANOVA with unequal sample sizes which was performed with R ( R Foundation for Statistical Computing, Vienna, Austria).

\section{SUPPLEMENTARY MATERIAL}

Supplementary material is linked to the online version of the paper at http:// www.nature.com/pr

\section{ACKNOWLEDGMENTS}

The authors recognize the expert technical assistance of Leon Smith (clinical research coordinator) and Shannon Bragg (laboratory assistant). P.P. and J.J. share first authorship of this manuscript.

\section{STATEMENT OF FINANCIAL SUPPORT}

This project was supported by the Loma Linda University Department of Pediatrics, Division of Neonatology, and by the National Institutes of Health, Bethesda, MD, Grant HL095973 (A.B.B.).

Disclosures: The authors have no conflicts of interest to disclose.

\section{REFERENCES}

1. Hall CN, Garthwaite J. What is the real physiological NO concentration in vivo? Nitric Oxide 2009;21:92-103.

2. Benjamin N, O'Driscoll F, Dougall H, et al. Stomach NO synthesis. Nature 1994;368:502. 
3. Kanady JA, Aruni AW, Ninnis JR, et al. Nitrate reductase activity of bacteria in saliva of term and preterm infants. Nitric Oxide 2012;27:193-200.

4. Lundberg JO, Weitzberg E. NO-synthase independent NO generation in mammals. Biochem Biophys Res Commun 2010;396:39-45.

5. Lundberg JO, Weitzberg E. Biology of nitrogen oxides in the gastrointestinal tract. Gut 2013;62:616-29.

6. Rassaf T, Ferdinandy P, Schulz R. Nitrite in organ protection. Br J Pharmacol 2014;171:1-11.

7. Kim-Shapiro DB, Gladwin MT. Mechanisms of nitrite bioactivation. Nitric Oxide 2014;38:58-68.

8. Neu J, Walker WA. Necrotizing enterocolitis. N Engl J Med 2011;364:255-64.

9. Neu J. The 'myth' of asphyxia and hypoxia-ischemia as primary causes of necrotizing enterocolitis. Biol Neonate 2005;87:97-8.

10. Patel AK, Lazar DA, Burrin DG, et al. Abdominal near-infrared spectroscopy measurements are lower in preterm infants at risk for necrotizing enterocolitis. Pediatr Crit Care Med 2014;15:735-41.

11. Nowicki PT. Ischemia and necrotizing enterocolitis: where, when, and how. Semin Pediatr Surg 2005;14:152-8.

12. Jones JA, Hopper AO, Power GG, Blood AB. Dietary intake and bio-activation of nitrite and nitrate in newborn infants. Pediatr Res 2015;77:173-81.

13. Doughty L, Carcillo JA, Kaplan S, Janosky J. Plasma nitrite and nitrate concentrations and multiple organ failure in pediatric sepsis. Crit Care Med 1998;26:157-62.

14. Figueras-Aloy J, Gómez L, Rodríguez-Miguélez JM, et al. Plasma nitrite/ nitrate and endothelin-1 concentrations in neonatal sepsis. Acta Paediatr 2003;92:582-7.

15. Kleinbongard P, Dejam A, Lauer T, et al. Plasma nitrite reflects constitutive nitric oxide synthase activity in mammals. Free Radic Biol Med 2003;35:790-6

16. Nowicki MJ, Shi D, Cai Z, Bishop PR, May WL. Developmental expression of endothelial nitric oxide synthase (eNOS) in the rat liver. Pediatr Res 2003;54:732-8.

17. Parker TA, le Cras TD, Kinsella JP, Abman SH. Developmental changes in endothelial nitric oxide synthase expression and activity in ovine fetal lung. Am J Physiol Lung Cell Mol Physiol 2000;278:L202-8.

18. Wu G, Jaeger LA, Bazer FW, Rhoads JM. Arginine deficiency in preterm infants: biochemical mechanisms and nutritional implications. J Nutr Biochem 2004;15:442-51.

19. Vida G, Sulyok E, Ertl T, Martens-Lobenhoffer J, Bode-Boger SM. Plasma asymmetric dimethylarginine concentration during the perinatal period. Neonatology 2007;92:8-13.

20. Blood $A B$, Tiso $M$, Verma $S T$, et al. Increased nitrite reductase activity of fetal versus adult ovine hemoglobin. Am J Physiol Heart Circ Physiol 2009;296:H237-46.

21. Huie RE, Padmaja S. The reaction of no with superoxide. Free Radic Res Commun 1993;18:195-9.

22. Donzelli S, Switzer CH, Thomas DD, et al. The activation of metabolites of nitric oxide synthase by metals is both redox and oxygen dependent: a new feature of nitrogen oxide signaling. Antioxid Redox Signal 2006;8:1363-71.

23. Toubas PL, Silverman NH, Heymann MA, Rudolph AM. Cardiovascular effects of acute hemorrhage in fetal lambs. Am J Physiol 1981;240:H45-8.
24. Sawa R, Asakura H, Power GG. Changes in plasma adenosine during simulated birth of fetal sheep. J Appl Physiol (1985) 1991;70:1524-8.

25. Padbury JF, Diakomanolis ES, Hobel CJ, Perelman A, Fisher DA. Neonatal adaptation: sympatho-adrenal response to umbilical cord cutting. Pediatr Res 1981;15:1483-7.

26. Lundberg JO, Carlström M, Larsen FJ, Weitzberg E. Roles of dietary inorganic nitrate in cardiovascular health and disease. Cardiovasc Res 2011;89:525-32.

27. Kelm M. Nitric oxide metabolism and breakdown. Biochim Biophys Acta 1999;1411:273-89.

28. Honold J, Pusser NL, Nathan L, Chaudhuri G, Ignarro LJ, Sherman MP. Production and excretion of nitrate by human newborn infants: neonates are not little adults. Nitric Oxide 2000;4:35-46.

29. Jones JA, Ninnis JR, Hopper AO, et al. Nitrite and nitrate concentrations and metabolism in breast milk, infant formula, and parenteral nutrition. JPEN J Parenter Enteral Nutr 2014;38:856-66.

30. Pennington J. Dietary exposure models for nitrates and nitrites. Food Control 1998;9:385-95.

31. Chobanyan-Jürgens K, Schwarz A, Böhmer A, et al. Renal carbonic anhydrases are involved in the reabsorption of endogenous nitrite. Nitric Oxide 2012;26:126-31.

32. Shah $\mathrm{P}$, Shah V. Arginine supplementation for prevention of necrotising enterocolitis in preterm infants. Cochrane Database Syst Rev 2007;CD004339.

33. Polycarpou E, Zachaki S, Tsolia M, et al. Enteral L-arginine supplementation for prevention of necrotizing enterocolitis in very low birth weight neonates: a double-blind randomized pilot study of efficacy and safety. JPEN J Parenter Enteral Nutr 2013;37:617-22.

34. Yazji I, Sodhi CP, Lee EK, et al. Endothelial TLR4 activation impairs intestinal microcirculatory perfusion in necrotizing enterocolitis via eNOSNO-nitrite signaling. Proc Natl Acad Sci USA 2013;110:9451-6.

35. Petrosyan M, Guner YS, Williams M, Grishin A, Ford HR. Current concepts regarding the pathogenesis of necrotizing enterocolitis. Pediatr Surg Int 2009;25:309-18.

36. Mishima S, Xu D, Lu Q, Deitch EA. Bacterial translocation is inhibited in inducible nitric oxide synthase knockout mice after endotoxin challenge but not in a model of bacterial overgrowth. Arch Surg 1997;132: $1190-5$.

37. Whitehouse JS, Xu H, Shi Y, et al. Mesenteric nitric oxide and superoxide production in experimental necrotizing enterocolitis. J Surg Res 2010;161:1-8.

38. Dzik JM, Dobrzańska A, Gruszfeld D, Walajtys-Rode E. Nitric oxide metabolites in the urine of full-term and preterm infants. Pediatr Int 2002;44:368-75.

39. Terry MH, Merritt TA, Harding B, et al. Pulmonary distribution of lucinactant and poractant alfa and their peridosing hemodynamic effects in a preterm lamb model of respiratory distress syndrome. Pediatr Res 2010;68:193-8.

40. Motulsky HJ, Brown RE. Detecting outliers when fitting data with nonlinear regression - a new method based on robust nonlinear regression and the false discovery rate. BMC Bioinformatics 2006;7:123. 